\title{
ENSO 事件对珠江中下游地区降水氢氧同位素的影响
}

\author{
郭政昇 ${ }^{1}$, 郑国璋 ${ }^{1,2}$, 曹富强 ${ }^{1}$, 赵 培 ${ }^{3}$, 肖 杰 $^{1}$ \\ (1. 山西师范大学地理科学学院,临汾 041004;2. 山西财经大学环境经济学院,太原 030006; \\ 3. 商洛学院城乡规划与建筑工程学院, 商洛 726000)
}

\begin{abstract}
摘要：水汽源区变化与 ENSO 事件显著影响季风区水循环过程。基于珠江中下游地区 4 个 GNIP 站点 (中国香港、广州、桂林、柳州) 的降水同位素及 OLR (向外长波辐射) 数据, 研究了 ENSO 背景下 $\delta^{18} \mathrm{O}$ 的时空分布特征及 ENSO 事件对降水中氢氧同位素特征的影响机制。结果 表明: ENSO 事件是影响稳定同位素年际差异的主要因素, 通过影响雨季降水的年内分配而实 现; 正常年大气降水线方程的斜率与截距均大于厄尔尼诺年而小于拉尼娜年; 拉尼娜年加强 $\delta^{18} \mathrm{O}$ 的反温度效应, 厄尔尼诺年减弱反温度效应; 厄尔尼诺与拉尼娜年热带辐合带的变化规律 呈现出相反的趋势, 其OLR场的变化与研究区稳定同位素特征有着较强的对应关系; ENSO事 件年不同的水汽源区相对湿度特征是造成 $d$ 值年际差异的主要因素。
\end{abstract}

关键词：稳定同位素;ENSO;OLR场;ITCZ;珠江中下游地区

氢氧稳定同位素是广泛存在于水体中的天然同位素, 因其分馏特征对环境变化有着 极为敏感的响应，贯穿于水循环的各个环节，被称为水的 “指纹”，是目前追踪大气降水 水汽来源及水循环过程的主要手段 ${ }^{[1]}$ 。随着同位素水文学研究的推进, 同位素示踪还被应 用于古气候恢复与季风环流反演的相关研究中，同位素水文学也成为未来水文学发展的 重要方向之一 ${ }^{[2]}$ 。降水稳定同位素的特征受水汽输送路径与降水地降水量、温度、湿度、 海拔等环境要素的影响, 反映大气水汽循环的全过程。近年来诸多学者的研究表明, 水 汽源区的变化与大尺度对流过程对降水稳定同位素的影响更为显著 ${ }^{[3]}$, 水汽源区位置和水 汽源区的降水冲刷作用, 是形成降水稳定同位素特征的深层原因 ${ }^{[4]}$ 。ENSO（El NiñoSouthern Oscillation）是全球海气耦合的最强信号之一, 也是年际气候变化中的最强信 号, 对东亚季风区的气候变化影响显著 ${ }^{[5]}$ 。

目前国内外对水汽源区变化/ENSO 与降水稳定同位素之间遥相关关系的研究取得了 较多成果。Kurita ${ }^{[6]}$ 、Tremoy 等 ${ }^{[7]}$ 和 Vimeux 等 ${ }^{[8]}$ 证明了水汽源区变化与降水 $\delta^{18} \mathrm{O}$ 之间存在显 著相关性, 并对其内在机制进行了初步探索; $\mathrm{GaO}$ 等 ${ }^{[9]}$ 和 $\mathrm{He}$ 等 ${ }^{[10]}$ 对青藏地区降水中的氢氧 同位素与北印度洋对流活动之间的关系进行了研究; 国内学者对珠江三角洲地区 ${ }^{[1]}$ 、洞 庭湖流域 ${ }^{[12]}$ 、上海 ${ }^{[13]}$ 地区的 ENSO 事件与降水中同位素组成与分布特征的关系进行初步研 究, 证明了ENSO 事件对降水稳定同位素的影响, 但其影响机制与规律仍不明确。向外 长波福射 OLR (Outgoing Longwave Radiation) 是从大气层外观测到的地气系统的对外 辐射, 是热带对流指示量, 也是热带环流异常的重要表征 ${ }^{[14]}$ 。相比于传统方法, OLR 技

收稿日期：2019-04-20；修订日期：2019-08-06

基金项目：山西师范大学科技开发与应用基金项目（ZK1402）；国家自然科学基金项目（41471188）

作者简介: 郭政昇 (1993-), 男, 山西大同人, 硕士, 研究方向为同位素水文学。E-mail: 1452952176@qq.com

通讯作者：郑国璋（1965-), 男, 山西洪洞人, 博士, 教授, 研究方向为同位素水文学。E-mail: shanxizgz@126.com 
术能够更精确地反映水汽源区热带辐合带（Intertropical Convergence Zone，ITCZ）的位 置与强度变化, 并广泛地应用于海气相互作用等方面的研究。因 OLR 对 ENSO 事件的过 程有着极为敏感响应，美国国家环境预报中心与日本气象厅等机构均将 OLR 技术用于 ENSO 事件的监测工作中 ${ }^{[15]}$ 。目前对于 OLR 资料的应用主要集中于气象领域，如：利用 OLR 数据, 确证夏季风期间阿拉伯海与印度的尘埃气溶胶及降雨的关系, 发现水汽源区 对南亚季风区尘埃和降雨的变化周期有着关键作用 ${ }^{[16]}$; 明确气候耦合模型中海表温度和 OLR 的关系，指出孟加拉湾对流过程受当地海一气耦合的支配 ${ }^{[17]}$; Tang 等 ${ }^{\left[{ }^{[18]}\right.}$ 将 OLR 技术应 用于同位素水文学研究中，对2012-2014年南京降水稳定同位素与水汽源区 ITCZ位置及强 度变化之间的相关性进行了探索。然而目前对水汽源区变化/ENSO 事件与 $\delta^{18} \mathrm{O}$ 相关机制 的研究仍不完善, 尚不明确 ENSO 事件对不同区域降水稳定同位素的影响程度及特征, 也需要用新的方法深人对水汽源区变化过程的探索，提高指示精度，完善对 ENSO 事件 发展过程的示踪。

本文依据珠江中下游地区内中国香港、广州、桂林和柳州四个站点降水同位素数 据，利用OLR 技术进一步探索水汽源区变化及 ENSO 事件对降水中同位素特征的影响， 能够深人了解我国季风区水汽来源及降水过程的变化, 有助于进一步推进对季风区水循 环机制的研究。

\section{1 研究方法与数据来源}

\section{1 研究区概况}

珠江地处华南沿海地区，是我国流量第二、流域面积第三的大河。珠江中下游地区 兼有热带和亚热带季风气候，年均温在 $14 \sim 22{ }^{\circ} \mathrm{C}$ 之间，降水量时空分布差异大，由东部 沿海向西部山区递减，4-9 月雨量约占全年 $80 \%$ 左右 ${ }^{[19]}$ 。由于珠江中下游地区是季风人境 首先经过的区域, 且大多属于平原丘陵地形, 受印度洋与太平洋两大水汽源区夏季风的 直接影响, 避免了远距离水汽输送过程及地形因素对同位素分馏的干扰, 能够更为突出 地表现水汽源区变化及ENSO 事件的影响机制，是理想的研究区域。

\section{2 数据来源}

中国加人全球大气降水同位素网络 (Global Network of Isotope in Precipitation, GNIP) 的站点中位于珠江中下游地区的有中国香港、广州、桂林、柳州 4 个站点。本研究所用 四个站点的相关数据部分由 IAEA 官网（http://iaea.org/water）下载，部分由近年来国内 学者所设立的降水同位素观测点 (广州、桂林) 提供, 其地理信息及降水稳定同位素数 据如表 1 所示。

\section{表 1 珠江中下游地区观测点地理信息}

Table 1 Geographical information of observation points in the middle and lower reaches of the Pearl River

\begin{tabular}{|c|c|c|c|c|c|c|}
\hline 站点 & 纬度 $/{ }^{\circ} \mathrm{N}$ & 经度 $/{ }^{\circ} \mathrm{E}$ & 海拔/m & 研究时段 & 样本数/个 & 数据来源 \\
\hline 中国香港 & 22.32 & 114.17 & 66 & $1980.01-2015.12$ & 432 & GNIP \\
\hline 广州 & 23.13 & 113.32 & 7 & $\begin{array}{l}\text { 1986.01-1989.12 } \\
2004.05-2006.12 ; \\
2007.01-2009.12\end{array}$ & 105 & $\begin{array}{l}\text { GNIP, 尹焕玲等 }{ }^{[20]} \text {; } \\
\mathrm{Xie}^{\text {等 }}{ }^{[21]}\end{array}$ \\
\hline 桂林 & 25.07 & 110.08 & 170 & $\begin{array}{l}\text { 1983.01-1990.12 } \\
1990.01-1998.02 ; \\
2010\end{array}$ & 206 & $\begin{array}{l}\text { GNIP, 涂林玲等 }{ }^{[22]} \text {; } \\
\text { 吴夏等 }{ }^{[23]}\end{array}$ \\
\hline 柳州 & 24.35 & 109.40 & 97 & 1988.01-1992.12 & 60 & GNIP \\
\hline
\end{tabular}


表 1 中，同位素 $\delta$ 值均以维也纳标准海洋水（V-SMOW）的千分差表示：

$$
\delta^{18} \mathrm{O}(\text { or } \delta \mathrm{D})=\left(R_{\text {水样 }} / R_{\mathrm{V}-\mathrm{Smow}}-1\right) \times 1000 \% \text { 。 }
$$

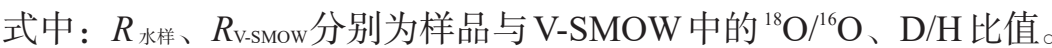

OLR 数据源自国家卫星气象中心提供风云二 $\mathrm{E}$ 地球同步轨道气象卫星，可见光红外自 旋扫描辐射仪所处理的月均向外长波辐射数据，空间分辨率为 $1^{\circ} \times 1^{\circ}$ 。卫星定位于 $105^{\circ} \mathrm{E}$, 能更好地反映我国及周边区域的水热状况及 ENSO 背景下水汽源区的演变过程。相对湿 度场来自美国国家环境预报中心的 NCEP/NCAR 再分析数据，空间分辨率为 $2.5^{\circ} \times 2.5^{\circ}$ 。

\subsection{ENSO 事件的划分依据与标准}

本文用 Niño 3.4 区海洋尼诺指数（Oceanic Niño index，ONI），即海表温度指数 （Sea Surface Temperature，SST）距平的 3 个月滑动平均值来定义ENSO 事件，参考南方 涛动指数（Southern Oscillation Index，SOI）计算海气强度指数。依美国气候预测中心标 准, $O N I$ 指数连续 5 个月 $\geqslant 0.5{ }^{\circ} \mathrm{C}$, 则定义为厄尔尼诺事件 (El Niño); ONI指数连续 5 个 月 $\leqslant-0.5{ }^{\circ} \mathrm{C}$, 则定义为拉尼娜事件 (La Niña)。依照 $O N I$ 与 $S O I$ 累计值的标准差计算海气 综合强度指数 (Oceanic Niño \& Southern Oscillation Composite Index, OSI)：

$$
O S I_{n}=\operatorname{Std}\left(\sum O N I\right)-\operatorname{Std}\left(\sum S O I\right)
$$

将海气综合强度指数 $O S I$ 作为划分 $\mathrm{ENSO}$ 事件强度的依据，参照陈虹预等 ${ }^{[24}$ 的分类方 法，按表 2 标准将 ENSO 事件分为极强、强、中等、弱、极弱 5 个等级，字母 E 代表各阶 段厄尔尼诺事件，字母 L 代表各阶段拉尼娜事件，最终划分结果如表 3 。

表 2 ENSO 事件的海气综合强度指标

Table 2 The OSI of ENSO events

\begin{tabular}{cccccc}
\hline 海气综合强度 & 极弱 & 弱 & 中等 & 强 & 极强 \\
\hline 厄尔尼诺事件 & $\leqslant-2.0$ & $-1.9 \sim-1.0$ & $-0.9 \sim 0.9$ & $1.0 \sim 1.9$ & $\geqslant 2.0$ \\
拉尼娜事件 & $\geqslant 2.0$ & $1.9 \sim 1.0$ & $0.9 \sim-0.9$ & $-1.0 \sim-1.9$ & $\leqslant-2.0$ \\
\hline
\end{tabular}

2 结果分析

\section{1 珠江中下游地区降水同位素特征分析}

\subsection{1 大气降水 $\delta^{18} \mathrm{O}$ 的季节变化}

对珠江中下游地区四个站点的 $\delta^{18} \mathrm{O}$ 、降水、气温数据分别按厄尔尼诺年、正常年、 拉尼娜年计算采样时段内多年月平均值，结果如图 1 所示。

总体而言，各站点 $\delta^{18} \mathrm{O}$ 值的时间变化趋势较为一致，1-12月表现为先波动下降再急 剧上升的过程，夏秋低、冬春高，最低值出现在 8 月或 9 月，最高值则出现在 2 月。各站 点 $\delta^{18} \mathrm{O}$ 值的水平在不同年份表现出较大差异，厄尔尼诺年显著高于正常年，拉尼娜年则 显著低于正常年，厄尔尼诺年与拉尼娜年 $\delta^{18} \mathrm{O}$ 值的差异性通过 0.05 显著性水平检验，证 明降水中 $\delta^{18} \mathrm{O}$ 值的水平敏感地反映了 $\mathrm{ENSO}$ 事件对季风气候的影响。 $\mathrm{ENSO}$ 事件对 $\delta^{18} \mathrm{O}$ 的 影响在雨季表现得更为明显，这是通过影响降水状况而实现的。由图 1 可见，各站点厄 尔尼诺年、正常年、拉尼娜年的气温差异并不显著，但除中国香港站外，雨季降水的时 间分布则差异明显。依据各事件年降水量数据，雨季前期（4-7月）与雨季后期（8-10 月）各事件年降水量所占比例如图 2 所示，可见除中国香港站外，厄尔尼诺年降水显著 
表 3 1980-2016 年厄尔尼诺事件和拉尼娜事件统计

Table 3 Statistics of El Niño and La Niña events from 1961 to 2016

\begin{tabular}{|c|c|c|c|c|c|c|c|c|c|c|}
\hline & 序号 & 起始年月 & $\begin{array}{c}\text { 持续时间 } \\
\text { (月) }\end{array}$ & $\begin{array}{l}O N I \\
\text { 极值 } \\
\end{array}$ & $\Sigma O N I$ 强度 & $\begin{array}{l}\text { 海温 } \\
\text { 强度 }\end{array}$ & $\begin{array}{c}S O I \\
\text { 极值 } \\
\end{array}$ & $\sum S O I$ & OSI & $\begin{array}{l}\text { 海气 } \\
\text { 强度 }\end{array}$ \\
\hline \multirow{10}{*}{$\begin{array}{c}\text { 厄尔尼诺 } \\
\text { 事件 }\end{array}$} & E1 & $1982.05-1983.06$ & 14 & 2.1 & 19.0 & 极强 & -6.0 & -37.60 & 4.08 & 极强 \\
\hline & E2 & 1986.09-1988.02 & 18 & 1.6 & 19.7 & 强 & -2.4 & -23.20 & 2.74 & 极强 \\
\hline & E3 & 1991.06-1992.07 & 14 & 1.6 & 14.1 & 强 & -4.7 & -21.90 & 1.73 & 强 \\
\hline & E4 & 1994.10-1995.03 & 6 & 1.0 & 4.6 & 弱 & -2.0 & -4.50 & -1.52 & 弱 \\
\hline & E5 & $1997.05-1998.05$ & 13 & 2.3 & 20.3 & 极强 & -4.4 & -30.30 & 3.55 & 极强 \\
\hline & E6 & $2002.06-2003.02$ & 9 & 1.3 & 8.5 & 中等 & -1.8 & -8.30 & -0.52 & 中等 \\
\hline & E7 & $2004.07-2005.04$ & 10 & 0.7 & 6.2 & 弱 & -5.2 & -9.50 & -0.76 & 中等 \\
\hline & E8 & 2006.09-2007.01 & 5 & 1.0 & 3.9 & 弱 & -2.1 & -4.80 & -1.60 & 弱 \\
\hline & E9 & $2009.07-2010.04$ & 10 & 1.3 & 9.0 & 中等 & -2.4 & -6.90 & -0.59 & 中等 \\
\hline & E10 & $2015.03-2016.05$ & 15 & 2.3 & 21.5 & 极强 & -3.6 & -23.10 & 3.01 & 极强 \\
\hline \multirow{7}{*}{$\begin{array}{c}\text { 拉尼娜 } \\
\text { 事件 }\end{array}$} & L1 & 1984.10-1985.06 & 9 & -1.1 & -6.9 & 弱 & 2.0 & 4.50 & 1.95 & 弱 \\
\hline & L2 & 1988.05-1989.05 & 13 & -1.8 & -16.0 & 中等 & 3.0 & -0.62 & -1.58 & 中等 \\
\hline & L3 & 1995.08-1996.03 & 8 & -1.0 & -6.2 & 弱 & 1.9 & 2.06 & 1.78 & 极弱 \\
\hline & L4 & $1998.07-2001.03$ & 33 & -1.6 & -32.7 & 极强 & 3.0 & -4.24 & 2.56 & 极强 \\
\hline & L5 & $2007.08-2008.06$ & 11 & -1.4 & -10.9 & 中等 & 4.4 & 0.59 & -1.06 & 中等 \\
\hline & L6 & $2010.07-2011.04$ & 10 & -1.4 & -11.1 & 中等 & 4.8 & -0.52 & -1.19 & 中等 \\
\hline & L7 & 2011.08-2012.03 & 8 & -0.9 & -5.6 & 弱 & 4.1 & 1.55 & -1.28 & 弱 \\
\hline
\end{tabular}
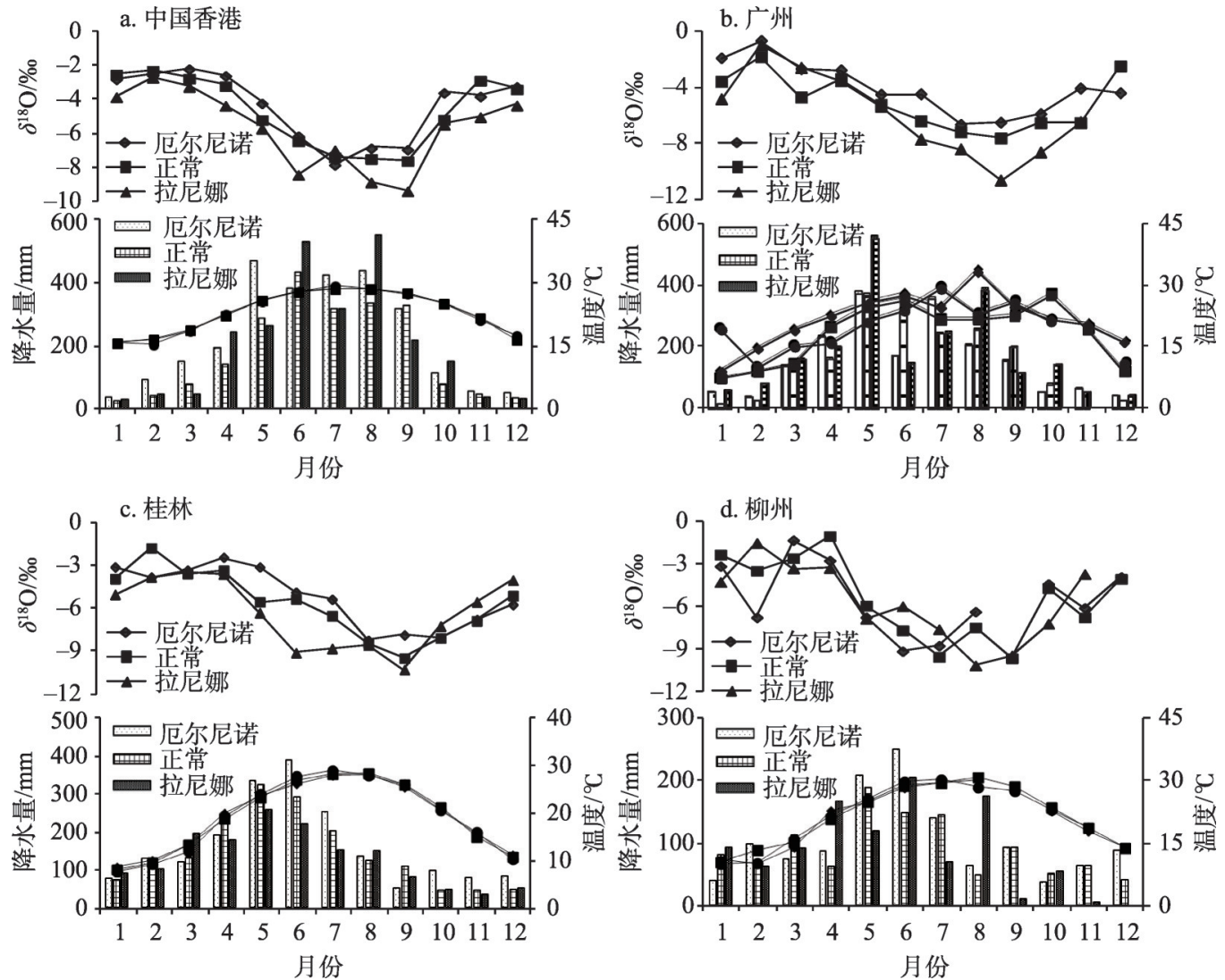

图 1 珠江中下游地区各站点大气降水 $\delta^{18} \mathrm{O}$ 、降水量、温度的多年平均变化

Fig. 1 The variations of $\delta^{18} \mathrm{O}, \delta \mathrm{D}$, precipitation and temprature in the middle and lower reaches of the Pearl River 
集中于雨季前期，而拉尼娜年降水在雨 季后期占主导地位，各事件年雨季前期 与后期的 $\delta^{18} \mathrm{O}$ 差异均通过 0.05 显著性水 平检验。由此可见, ENSO 事件对大气 降水 $\delta^{18} \mathrm{O}$ 的影响主要通过影响降水的年 内分布，特别是雨季降水的时间分布状 况而实现。

\subsection{2 大气降水线方程的差异}

大气降水中 $\delta \mathrm{D}$ 和 $\delta^{18} \mathrm{O}$ 之间的线性关 系被称作大气降水线方程。因降水中的 同位素分馏状况及比率变化受降水区自

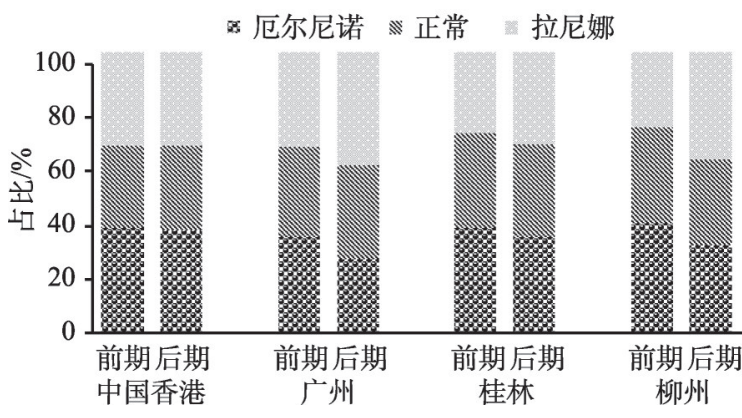

图 2 四个站点雨季前后期各事件年平均降水量对比

Fig. 2 Comparison of annual mean precipitation of each event year in prophase and anaphase of rainy season 然环境要素的影响，大气降水线方程代表着稳定同位素与地理特征之间的独特关系，深 刻地反映不同地域独特的降水特征 ${ }^{[25]}$ 。依据四个站点 140 组月均数据, 得到厄尔尼诺年、 正常年、拉尼娜年大气降水线方程为:

$$
\begin{array}{ll}
\text { 厄尔尼诺年: } \delta \mathrm{D}=8.22 \delta^{18} \mathrm{O}+10.19 & \left(R^{2}=0.91\right) \\
\text { 正常年: } \delta \mathrm{D}=8.30 \delta^{18} \mathrm{O}+11.70 & \left(R^{2}=0.95\right) \\
\text { 拉尼娜年: } \delta \mathrm{D}=8.73 \delta^{18} \mathrm{O}+14.51 & \left(R^{2}=0.97\right)
\end{array}
$$

图 3 为珠江中下游地区 $\delta \mathrm{D}-\delta^{18} \mathrm{O}$ 间的线性关系，可见厄尔尼诺年的斜率与截距均小于 正常年，拉尼娜年的斜率与截距均大于正常年，表明 ENSO 事件对降水中稳定同位素的 分馏状况有着规律性的影响，造成这一差异的原因可能是由于 ENSO 事件改变了珠江中 下游地区降水的年内分配状况。厄尔尼诺年降水集中于雨季前期，是旱季向雨季转换的 季节，蒸发旺盛，雨水在降落过程中受到二次蒸发，从而使厄尔尼诺年的斜率与截距降 低。拉尼娜年降水集中于雨季后期，水汽蒸发趋缓，局地再循环水汽在降水中的比例也 随之下降，从而推高了拉尼娜年的斜率与截距。依据厄尔尼诺和拉尼娜事件发生期间的 数据, 对不同事件年大气降水线的斜率和截距进行差异性 $T$ 检验，未能通过 0.05 显著性 水平检验，这与上海站表现一致; 而上海大气降水线方程厄尔尼诺年的斜率与截距在数 值上大于非厄尔尼诺年 ${ }^{[13]}$ ，这与本文结论相反。由此可见，ENSO 事件对大气环流的影响 极为复杂, 其对大气降水线方程的影响因地区而异，这一规律还有待于进一步研究。与 Yurtsever 等 ${ }^{206}$ 获得的全球大气降水线方程（ $\delta \mathrm{D}=8.17 \delta^{18} \mathrm{O}+10.56 ）$ 相比，厄尔尼诺斜率与 截距与之极为相近，非厄尔尼诺年 斜率与截距则相对较高; 与 Liu等 ${ }^{[2]}$ 提出的中国降水线方程 $(\delta \mathrm{D}=$ $\left.7.48 \delta^{18} \mathrm{O}+1.01\right)$ 和柳鉴容等 ${ }^{[28]}$ 所报道 的中国东部季风区降水线方程 $(\delta \mathrm{D}=$ $\left.7.46 \delta^{18} \mathrm{O}+0.90\right)$, 以及中国大气降水 同位素观测网络 (CHNIP) 站点西 双版纳 ${ }^{[2]}\left(\delta \mathrm{D}=7.82 \delta^{18} \mathrm{O}+7.00\right)$ 相 比, 斜率与截距均较高。综合来 看，只在厄尔尼诺年与全球大气降 水线方程相近，而总体上较中国各

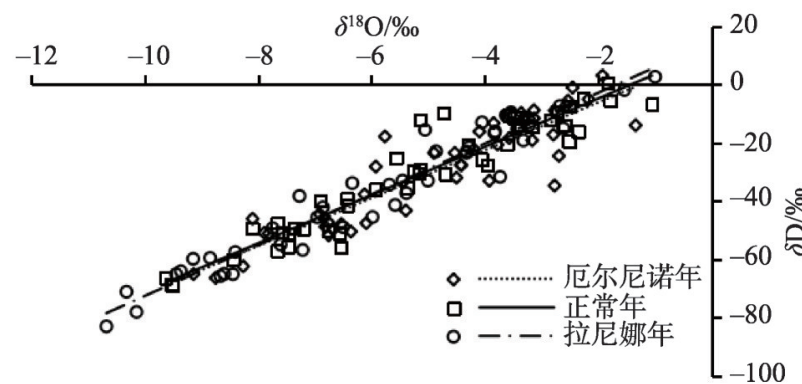

图 3 珠江中下游地区大气降水线方程

Fig. 3 Local Meteoric Water Lines (LMWL) of the middle and lower reaches of the Pearl River 
地大气降水线方程显著较高的斜率与截距，体现出暖湿性的气候特征。

\subsection{3 大气降水 $\delta^{18} \mathrm{O}$ 的环境效应}

在影响大气降水稳定同位素的诸多自然因子中，温度与降水量对同位素分馏比率的 影响最为显著。依据各站点月均数据，分析珠江中下游地区在厄尔尼诺年、正常年、拉 尼娜年的 $\delta^{18} \mathrm{O}$ 与降水量、温度的关系，结果见表 4 :

在各事件年的全年尺度上，除中国香港站全部通过 0.05 显著性水平检验外，各站点 都只有正常年与拉尼娜年 $\delta^{18} \mathrm{O}$ 与温度的关系通过显著性水平检验，因此珠江中下游地区 大气降水 $\delta^{18} \mathrm{O}$ 的环境效应以反温度效应为主，这与郭政昇等 ${ }^{[25]}$ Z ZHANG 等 ${ }^{[29}$ 的研究结果 一致。除中国香港站各事件年 $\delta^{18} \mathrm{O}$ 与气温的相关系数 $\left(R_{\delta-T}^{2}\right)$ 及 $\delta^{18} \mathrm{O}$ 与降水量的相关系数 $\left(R_{\delta-P}^{2}\right)$ 基本保持稳定外，ENSO 事件对其余站点的反温度效应影响显著，拉尼娜年与正 常年 $R_{\delta-T}^{2}$ 都通过了显著性检验，且拉尼娜年 $R^{2}{ }_{\delta-T}$ 显著大于正常年，而厄尔尼诺年 $R_{\delta-T}^{2}$ 则均 未通过检验，可见拉尼娜年加强反温度效应，厄尔尼诺年减弱反温度效应。值得注意的 是, 中国香港站反温度效应与降水量效应都很显著, 且 ENSO 事件年对环境效应的影响 并不大，图 2 中中国香港站雨季前期与后期各事件年平均降水量的对比也并无明显差 异。张冲 ${ }^{[30]}$ 对我国不同区域气温、降水量变化与 ENSO 事件的关系进行了研究, 同样发 现 ENSO 事件对华南广东沿海地区降水量的影响很弱。因此, 中国香港站的诸多特殊表 现可能与其所处的独特地理位置有关，中国香港气候属于海滨型 ${ }^{[31]}$, 无论 ENSO 事件如 何变化, 都是水汽首先登陆的地区, 降水充沛, 受水汽源区变化带来的影响很小; 内陆 地区则在不同程度上受 ENSO 事件的影响, 越是深人内陆, 水汽输送强度与雨带范围的 年际波动越大，这也与 ENSO 事件对我国不同区域气候的影响相一致 ${ }^{[30]}$ 。但这一推论目 前尚待更为确切的研究子以证实。

\subsection{ENSO 事件对珠江中下游地区降水中 $\delta^{18} O$ 的影响}

\subsubsection{ENSO事件与降水中 $\delta^{18} \mathrm{O}$ 的关系}

在影响降水稳定同位素特征的诸多因素中，水汽源区变化首先影响稳定同位素的分 馏状况，水汽团运移过程与降水区环境特征都是在其基础上，对降水中稳定同位素特征

表 4 珠江中下游地区大气降水 $\boldsymbol{\delta}^{18} \mathrm{O}$ 与气象要素的相关性

Table 4 Correlation between $\delta^{18} \mathrm{O}$ and meteorological elements in the middle and lower reaches of the Pearl River

\begin{tabular}{llllll}
\hline 站点 & 年份 & $\delta^{18} \mathrm{O}$ 与降水量 & $R_{\delta-P}^{2}$ & $\delta^{18} \mathrm{O}$ 与温 & $R_{\delta-T}^{2}$ \\
\hline 中国香港 & 厄尔尼诺 & $\delta^{18} \mathrm{O}=-0.01 P-3.16$ & $0.29^{*}$ & $\delta^{18} \mathrm{O}=-0.32 T+3.08$ & $0.44^{*}$ \\
& 正常 & $\delta^{18} \mathrm{O}=-0.01 P-3.25$ & $0.40^{*}$ & $\delta^{18} \mathrm{O}=-0.38 T+4.08$ & $0.49^{*}$ \\
& 拉尼娜 & $\delta^{18} \mathrm{O}=-0.01 P-4.29$ & $0.30^{*}$ & $\delta^{18} \mathrm{O}=-0.38 T+2.89$ & $0.42^{*}$ \\
\multirow{2}{*}{ 广州 } & 厄尔尼诺 & $\delta^{18} \mathrm{O}=-0.01 P-3.48$ & 0.10 & $\delta^{18} \mathrm{O}=-0.13 T-1.64$ & 0.11 \\
& 正常 & $\delta^{18} \mathrm{O}=-0.01 P-3.78$ & $0.27^{*}$ & $\delta^{18} \mathrm{O}=-0.06 T-4.08$ & $0.29^{*}$ \\
& 拉尼娜 & $\delta^{18} \mathrm{O}=-0.01 P-4.66$ & 0.13 & $\delta^{18} \mathrm{O}=-0.26 T+0.57$ & $0.42^{*}$ \\
桂林 & 厄尔尼诺 & $\delta^{18} \mathrm{O}=0.01 P-5.56$ & 0.03 & $\delta^{18} \mathrm{O}=-0.10 T-3.25$ & 0.07 \\
& 正常 & $\delta^{18} \mathrm{O}=0.01 P-6.32$ & 0.02 & $\delta^{18} \mathrm{O}=-0.21 T-1.69$ & $0.22^{*}$ \\
& 拉尼娜 & $\delta^{18} \mathrm{O}=-0.01 P-5.56$ & 0.03 & $\delta^{18} \mathrm{O}=-0.25 T-1.62$ & $0.51^{*}$ \\
\cline { 3 - 3 } & 厄尔尼诺 & $\delta^{18} \mathrm{O}=-0.01 P-4.22$ & 0.15 & $\delta^{18} \mathrm{O}=-0.19 T-2.16$ & 0.17 \\
& 正常 & $\delta^{18} \mathrm{O}=-0.02 P-3.82$ & 0.10 & $\delta^{18} \mathrm{O}=-0.31 T+1.44$ & $0.47^{*}$ \\
& 拉尼娜 & $\delta^{18} \mathrm{O}=-0.01 P-4.94$ & 0.07 & $\delta^{18} \mathrm{O}=-0.30 T+0.74$ & $0.62^{*}$ \\
\hline
\end{tabular}

注: “表示通过 0.05 显著性水平检验。 
进行再塑造。就水汽源区变化的影响而言, ENSO 事件无疑是最为显著的因子, 对水汽 源区的季节性演变和区域乃至全球的降水、气温等气候要素的异常有着密切关系 ${ }^{[2]}$, 并 直接影响着水循环中稳定同位素的分馏状况与特征。综合考虑降水同位素与风云二 $\mathrm{E}$ 气 象卫星数据的起止时间，因 ENSO 事件多为跨年度发生，且转换时间一般为夏半年，制 成2015-2016年、2014-2015 年、2010-2011年7月、10月、1月、4月 OLR场图，分别代 表厄尔尼诺年、正常年与拉尼娜年水汽源区的年内变化状况。需要说明的是，2015-2016 年厄尔尼诺事件为极强, 其 OLR 场表现较拉尼娜年更为极端, 但也更加凸显其变化规 律, 结果如图4所示。

因孟加拉湾水汽源区为影响研究区气候的主要水汽源区, 且西太平洋水汽源区与其

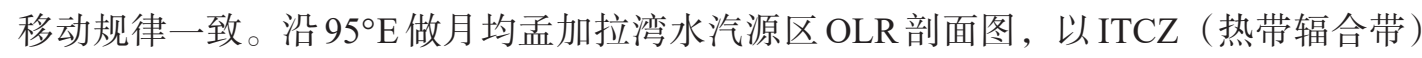
低值点为中心, 南北各跨约 $15^{\circ}$ 。各事件年沿 $95^{\circ} \mathrm{E}$ 水汽源区 OLR 场剖面如图 5 (为突出 展示 OLR 低值中心, 各剖面纵坐标为逆序刻度, 最高点即为 OLR 最低值, 图中颜色为区 分各月)。

由图 4、图 5 可见, 同月份在不同 $\mathrm{ENSO}$ 事件背景下, 水汽源区状况有显著差异, 其 OLR 值总体上呈现出厄尔尼诺年>正常年>拉尼娜年的特征, 这与图 2 中各站点在不同年 份背景下表现出的 $\delta^{18} \mathrm{O}$ 值水平差异相一致, 证明 $\mathrm{ENSO}$ 事件背景下水汽源区的变化对 $\delta^{18} \mathrm{O}$ 值的年际变化有着很大的影响。

具体来看, 7 月代表的夏季是气温最高、降水较多的季节, 此时厄尔尼诺年水汽源 区的 OLR 场表现为高值区域，无明显的水汽中心，而正常年与拉尼娜年则建立了明显的 ITCZ。正常年孟加拉湾与西太平洋水汽源连为一体, 西太平洋 OLR 低值区程度更深, 水 汽辐合更强, 而拉尼娜年则相对较弱, 孟加拉湾低值区辐合更强, 表明正常年与拉尼娜 年水汽源区特征差异显著。这一时期各站点正常年与拉尼娜年降水量总体大于厄尔尼诺 年, 由沿海向内陆这一特点更趋明显。图 1 中广州与桂林厄尔尼诺年的 $\delta^{18} \mathrm{O}$ 值表现为厄尔 尼诺年 $>$ 正常年>拉尼娜年，柳州站同样呈现厄尔尼诺年上升而拉尼娜年下降的过程。而 中国香港站则在 3-10月表现为厄尔尼诺年>正常年>拉尼娜年的规律, 却在 7 月呈现拉尼 娜年>正常年>厄尔尼诺年的倒置状态，是其特殊性的又一表现。在夏半年这一时期，也 是 OLR 与 $\delta^{18} \mathrm{O}$ 值的差异表现最为显著的时期。

10 月代表的秋季是气温与降水逐步降低的阶段, 此时水汽源区已经南移, 副高已经 控制华南地区，厄尔尼诺年与正常年 ITCZ 显著减弱，而拉尼娜年则十分明显。这一时期 降水的差异并不显著, 但除香港外, 其他三个站点的 $\delta^{18} \mathrm{O}$ 值则出现了拉尼娜年高于正常 年与厄尔尼诺年的现象, 特别是桂林与柳州两个内陆站点表现的尤为显著。这应与水汽 源区的位置特征有关, 拉尼娜年辐合带范围更广、更偏北且程度更深, 海温相对较高且 水汽运移路线相对于正常年与厄尔尼诺年更短, 稳定同位素在水汽团运移过程中贫化程 度更低, 从而推高了 $\delta^{18} \mathrm{O}$ 值。

1 月代表的冬季是是气温与降水最低的季节, $10^{\circ} \mathrm{N}$ 地区由副高控制, ITCZ退至赤道 地区, 厄尔尼诺年辐合中心极为微弱, 而正常年与拉尼娜年则较为明显。这一时期降水 差异同样不显著, 拉尼娜年辐合带保持着范围更广、更偏北且程度更深的特点, 广州、 桂林、柳州三个站点同样出现了 $\delta^{18} \mathrm{O}$ 值拉尼娜年高于正常年与厄尔尼诺年的现象，中国 香港站 $\delta^{18} \mathrm{O}$ 值也急剧升高。 

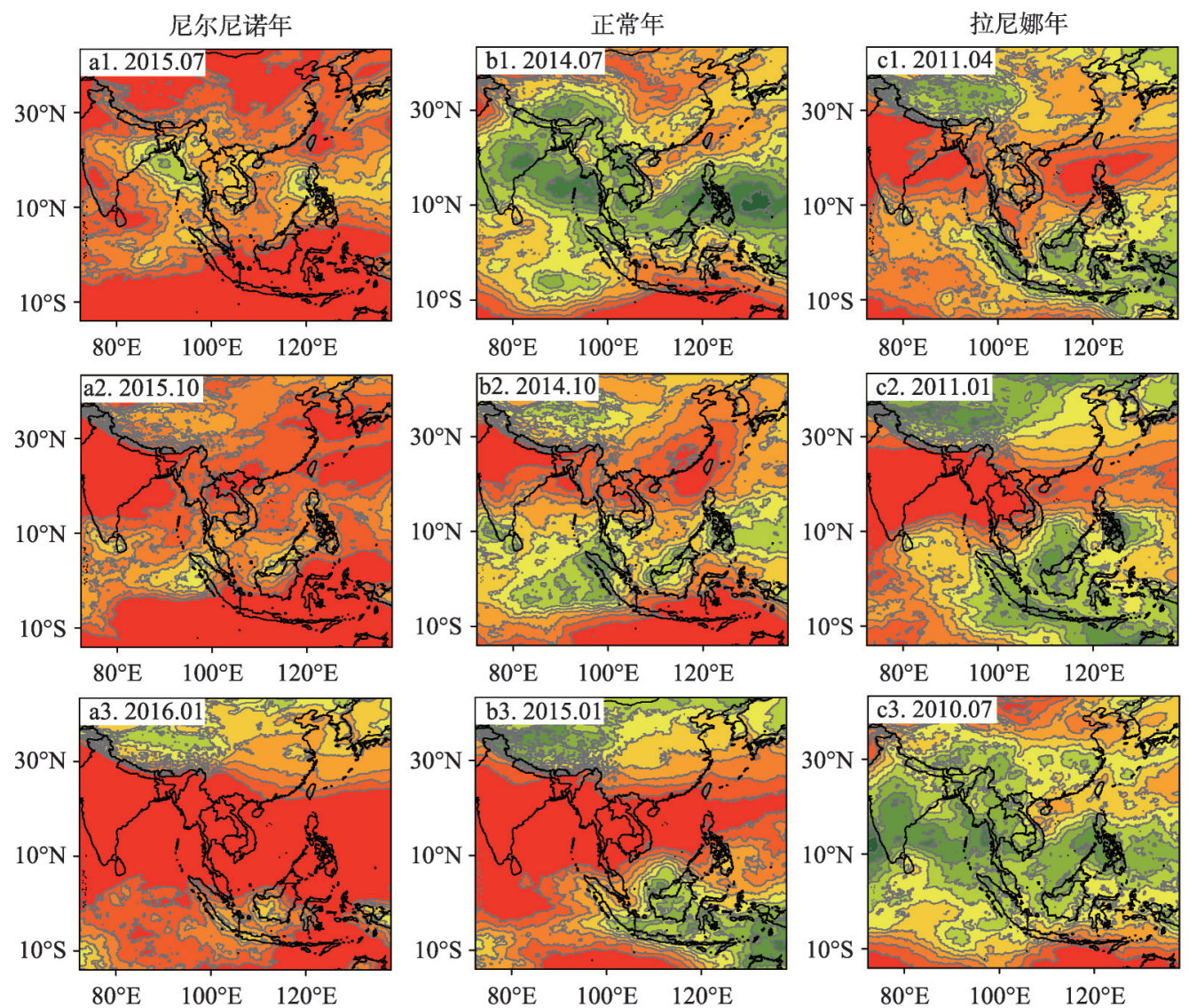

$80^{\circ} \mathrm{E} \quad 100^{\circ} \mathrm{E} \quad 120^{\circ} \mathrm{E}$
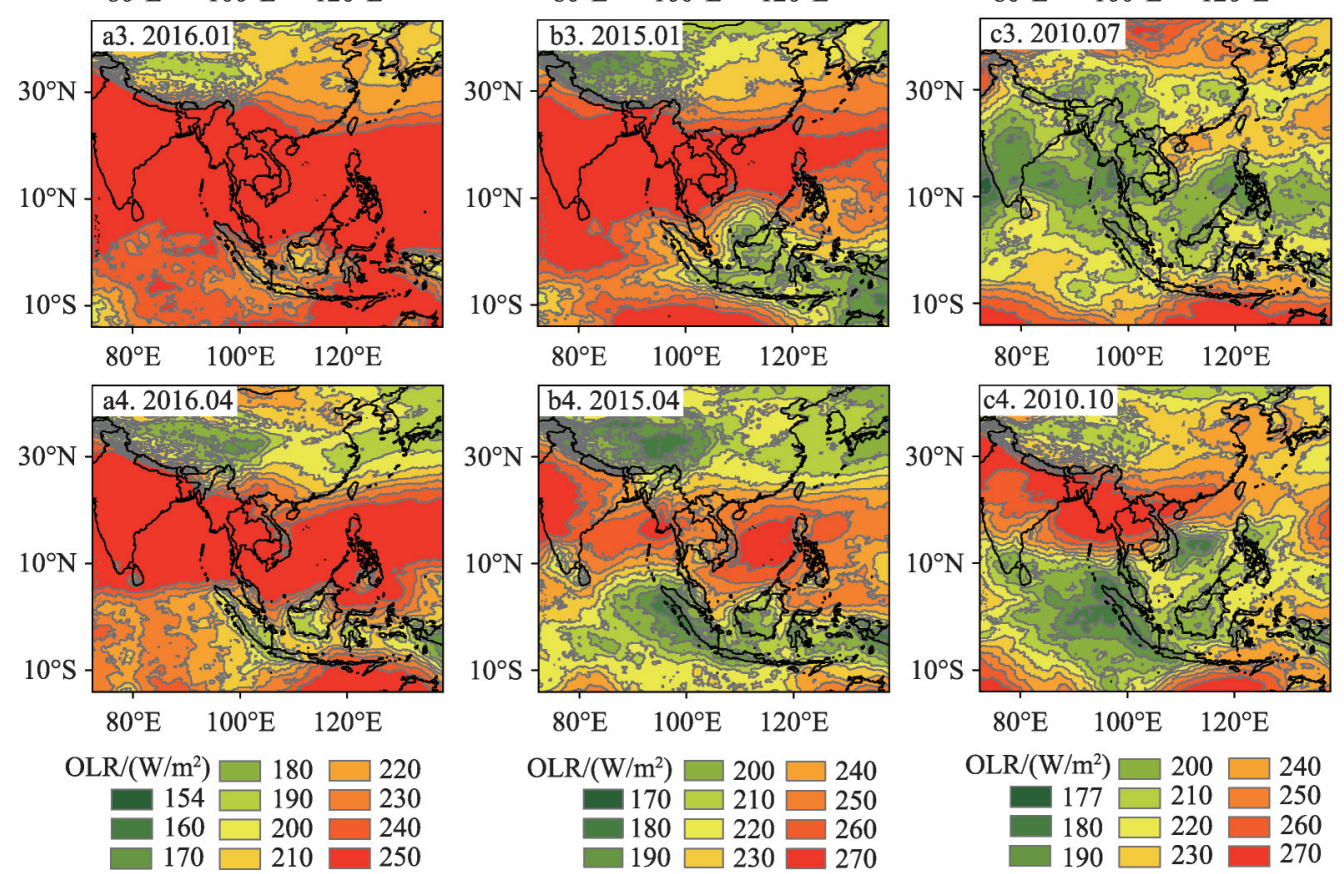

$80^{\circ} \mathrm{E} \quad 100^{\circ} \mathrm{E} \quad 120^{\circ} \mathrm{E}$

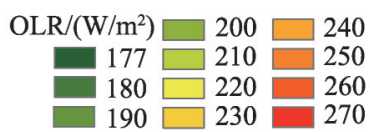

注：本图基于国家基础地理信息中心网站下载的审图号为 GS(2016)1666 号的标准地图制作，底图无修改，下同。

图 4 水汽源区 OLR 平均场图

Fig. 4 OLR mean field diagram of moisture sources

4 月代表的春季是气温与降水逐步升高的阶段, 此时副高减弱, ITCZ北移，厄尔尼 诺年辐合中心逐渐加强, 正常年与拉尼娜年较为明显, 正常年 ITCZ加深, 厄尔尼诺年 $\mathrm{ITCZ}$ 至 5 月方才建立，降水也随之增多。这一时期随着孟加拉湾水汽源区的发展，降水 渐多而 $\delta^{18} \mathrm{O}$ 值渐低, $\delta^{18} \mathrm{O}$ 值水平全部恢复为厄尔尼诺年>正常年>拉尼娜年的状态。

为进一步确证降水稳定同位素与水汽源区的对流强度之间的联系，分别计算各站点 不同事件年 $\delta^{18} \mathrm{O}$ 值与水源区 OLR 场之间的空间相关性（图 6), 只显示通过 0.05 显著性水 

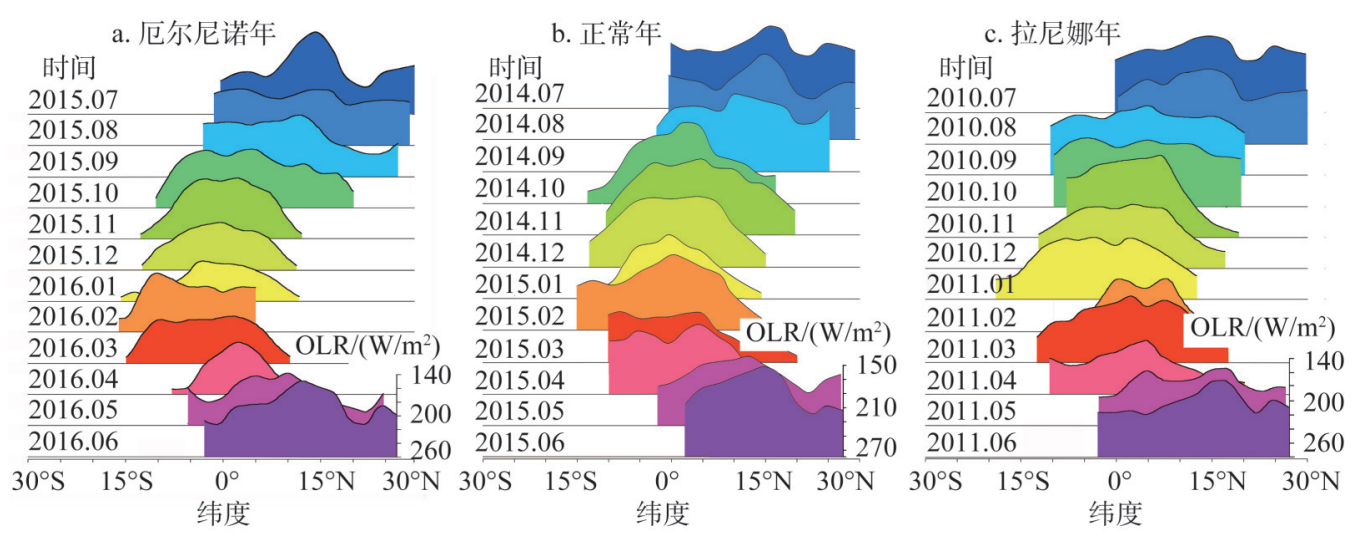

图 5 沿 $95^{\circ} \mathrm{E}$ 水汽源区 $\mathrm{OLR}$ 场剖面图

Fig. 5 OLR profile of the moisture sources along the $95^{\circ} \mathrm{E}$

平检验的数据。总体来看，各站点各事件年 $\delta^{18} \mathrm{O}$ 值与 OLR 场所反演的水汽源区 ITCZ变化 呈高度负相关，表现为厄尔尼诺年通过相关性检验的范围相对较小，负相关系数也较 低; 拉尼娜年通过相关性检验的范围显著扩大，负相关系数普遍较高，且位置主要位于 西太平洋水汽源区。证明厄尔尼诺年 ITCZ 强度较低, 而拉尼娜年西太平洋 ITCZ 发展强 盛，对珠江中下游地区 $\delta^{18} \mathrm{O}$ 值具有显著的影响。

基于以上对 OLR 场各事件年内变化规律的分析，为进一步确证水汽源区的位置及其 在不同 ENSO背景下的总体变化状况，依据各事件年 12 个月份的月均 OLR 场和相对湿度 场，得到各事件年的年均 OLR 场和相对湿度场，并分别计算厄尔尼诺年/拉尼娜年与正常 年的差值, 结果如图6。
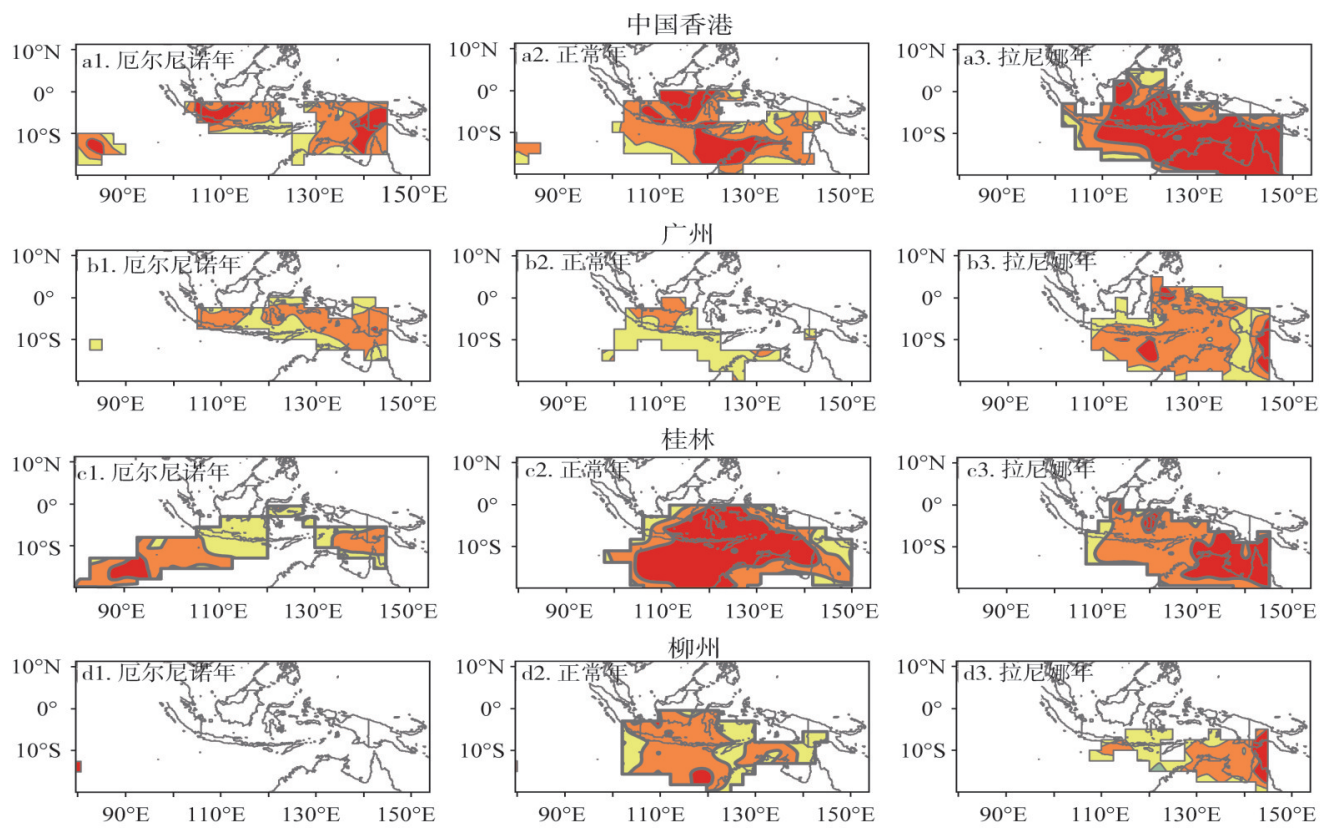

相关系数 $\square-0.6 \square-0.7 \square-0.8 \square-0.9$

图 6 珠江中下游地区各站点 $\delta^{18} \mathrm{O}$ 与 OLR 场的空间显著相关性结果

Fig. 6 Spatial correlation between $\delta^{18} \mathrm{O}$ and OLR fields of four stations 
从 ENSO 事件的发展过程来看，与正常年相比，厄尔尼诺与拉尼娜年 ITCZ的变化规 律呈现出相反的趋势。由图 4、图 5 可见，厄尔尼诺年 ITCZ在 4 月开始建立并加深，至 7 月达到最盛，而 10 月则较弱; 正常年在 7 月和 4 月左右是 ITCZ 程度最深的阶段；拉尼娜 年 ITCZ 则在 10 月达到最盛, 1 月仍保持着较大的范围。因此, 厄尔尼诺年 ITCZ 主要建 立并加深在春夏季, 且总体偏南, 规模较小; 而拉尼娜年ITCZ 则在秋季达到一年中的峰 值, 总体偏北, 范围较大。厄尔尼诺年对降水和 $\delta^{18} \mathrm{O}$ 值的影响主要体现在雨季前期, 而 拉尼娜年主要体现在雨季的后期，这与本文的分析结果一致。

图 6a所反映的厄尔尼诺年与正常年的 OLR 差值主要体现在西太平洋, 印度洋水汽源区 差值与范围相对较小, 主要位于赤道附近地区, 其OLR 均值较正常年偏高 $10 \sim 15 \mathrm{~W} / \mathrm{m}^{2}$ 。 拉尼娜年（图 6b）OLR 差值同样体现在西太平洋水汽源区，且范围更大，强度更深，其 OLR 均值较正常年偏低 $20 \mathrm{~W} / \mathrm{m}^{2}$ 左右, 而印度洋水汽源区的波动范围与强度相较于厄尔 尼诺年都明显减弱。各事件年相对湿度场的变化规律与范围同 OLR 场保持一致，厄尔尼 诺年水汽源区相对湿度减少 $5 \%$ 左右，拉尼娜年相对湿度则升高 $6 \%$ \% 。由图 6 可知，拉 尼娜年水汽源区位置要更靠北，接近 $10^{\circ} \mathrm{N}$ 左右，西太平洋水汽源区的波动范围与强度都 远大于印度洋水汽源区, 因此印度洋水汽源区较为稳定, 西太平洋水汽源区位置与相对 湿度的变化是ENSO 事件年中影响研究区降水稳定同位素变化的主要因子。

\subsubsection{ENSO 事件强度对降水同位素特征的影响}

水汽源区在不同事件年对研究区大气降水稳定同位素有着重要的影响 (图7), 但不同 强度特征的 ENSO 事件对同位素水平、特征的影响则尚未明确。在指示 ENSO 事件强度指 标中, 选取 $\Sigma O N I$ (标准化海洋尼诺指数) 代表水汽源区 ENSO事件的强度值。大气降水中 $\delta \mathrm{D}$ 和 $\delta^{18} \mathrm{O}$ 之间的差值称为氞盈余 $(d)$, 在水汽团运移过程中，因动力与热力分馏的不同造
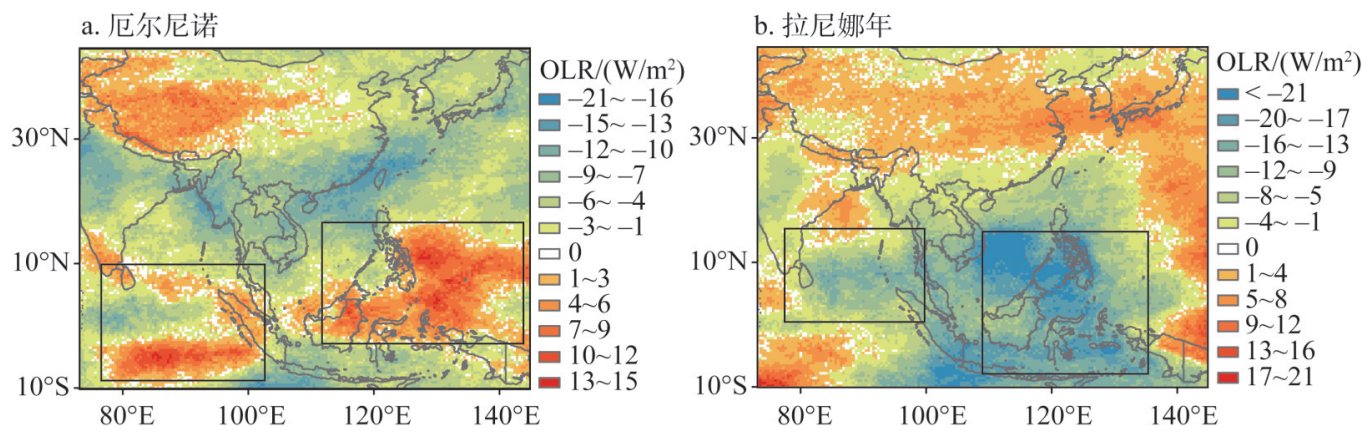

c. 万尔尼诺年

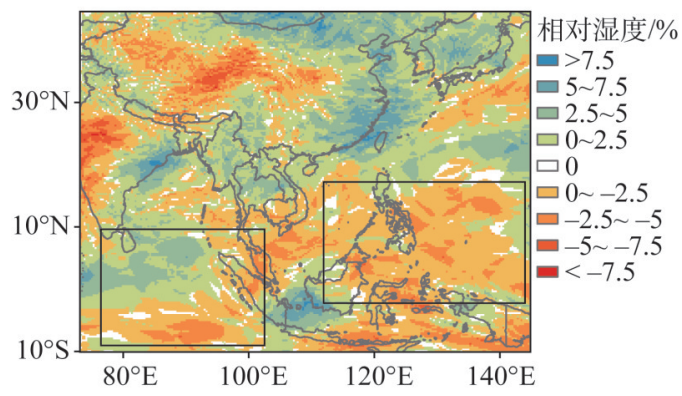

d. 拉尼娜年

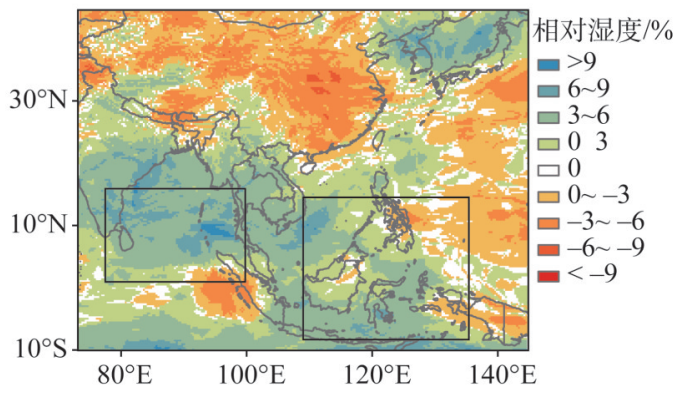

图 $7 \mathrm{ENSO}$ 事件年与正常年的 OLR 场 $\left(\mathrm{W} / \mathrm{m}^{2}\right)$ 与相对湿度场 $(\%)$ 差值, 方框内为主要水汽源区

Fig. 7 Difference between ENSO event year and normal year OLR $\left(\mathrm{W} / \mathrm{m}^{2}\right)$ and relative humidity $(\%)$ field

(The main moisture sources is in the square box.) 
成氝盈余的特征差异 ${ }^{[33]}$ 。Dansgaard ${ }^{[34]}$ 定义忥盈余为 : $d=\delta \mathrm{D}-8 \delta^{18} \mathrm{O}(\%)$, 它既能反映海水 蒸发形成的热力条件和水汽平衡条件, 又能反映降水形成时的地理环境和气候条件 ${ }^{[35]}$ 。

计算各事件年 $\delta^{18} \mathrm{O}$ 值、 $d$ 值、 $\Sigma O N I$ 指数、降水量及气温的多年月平均值，其变化如 图 8 所示，对 $\delta^{18} \mathrm{O} 、 d$ 值与 $\Sigma O N I$ 指数做回归分析，并计算 $\Sigma O N I$ 指数与其他各值之间的相 关性。

$\mathrm{ENSO}$ 事件期间， $d$ 值与 $\Sigma O N I$ 的绝对值呈现较为显著的负相关（拉尼娜年 $\Sigma O N I$ 为负 值)，即 ENSO 事件强度越大， $d$ 值越小， $\delta^{18} \mathrm{O}$ 与 $\Sigma O N I$ 绝对值的关系同为负相关，其回归 方程为:

$\begin{array}{cc}\text { 厄尔尼诺年: } \delta^{18} \mathrm{O}=-0.31 \Sigma O N I-4.22 & (R=0.34) \\ d=-0.15 \Sigma O N I+14.31 & (R=0.35) \\ \text { 拉尼娜年: } \delta^{18} \mathrm{O}=0.04 \Sigma O N I-6.18 & (R=0.45) \\ d=0.05 \Sigma O N I+12.55 & (R=0.25)\end{array}$

厄尔尼诺年 $\delta^{18} \mathrm{O}$ 受 $\Sigma O N I$ 的影响更为显著，而拉尼娜年 $d$ 值受 $\Sigma O N I$ 的影响更为显著， 这是由水汽源区在不同事件年表现出的特征所决定的。 $d$ 值的大小主要由水汽源区的相 对湿度决定, 相对湿度较低的源区使水汽遭受了较为强烈的蒸发过程, 并在运移过程中 存在着二次蒸发，稳定同位素分馏并推高了 $d$ 值; 而相对湿度较高的源区则分馏程度较 低, $d$ 值也随之降低 ${ }^{[36]}$, 因此将 $d$ 值作为判断水汽源区状况的依据。厄尔尼诺年水汽源区 OLR场明显较高，水汽相对湿度也较小（图 7c)，降水主要集中在雨季前期，因而 $d$ 值总 体较高, 降水量效应相对突出, $\Sigma O N I$ 与 $\delta^{18} \mathrm{O}$ 、降水量之间的相关系数分别为 $0.32 、 0.4$, 相对其他因素较高。拉尼娜年水汽源区 OLR场较低，降水集中于雨季后期，水汽相对湿 度也较大 (图 7d), $d$ 值显著低于厄尔尼诺年，因此 $\Sigma O N I$ 与 $d$ 值间的相关系数大于 $\delta^{18} \mathrm{O}$ 。 需要说明的是, 在 ENSO 事件形成早期, 海温异常而引起海一气耦合系统对水汽输送的 影响总会滞后一段时间出现 ${ }^{[37]}, d$ 值对 ENSO指数 $\Sigma O N I$ 的响应也存在一定的滞后性，因 此对 $d$ 值与 $\Sigma O N I$ 相关性有着很大影响。ENSO 事件发生时不同的水汽源区的位置与相对 湿度特征是 $d$ 值年际差异的主要因素, 这也与 OLR 场与相对湿度场的特征一致, 同时也 再次印证了ENSO 事件主要通过降水的年内分配状况来影响同位素特征。

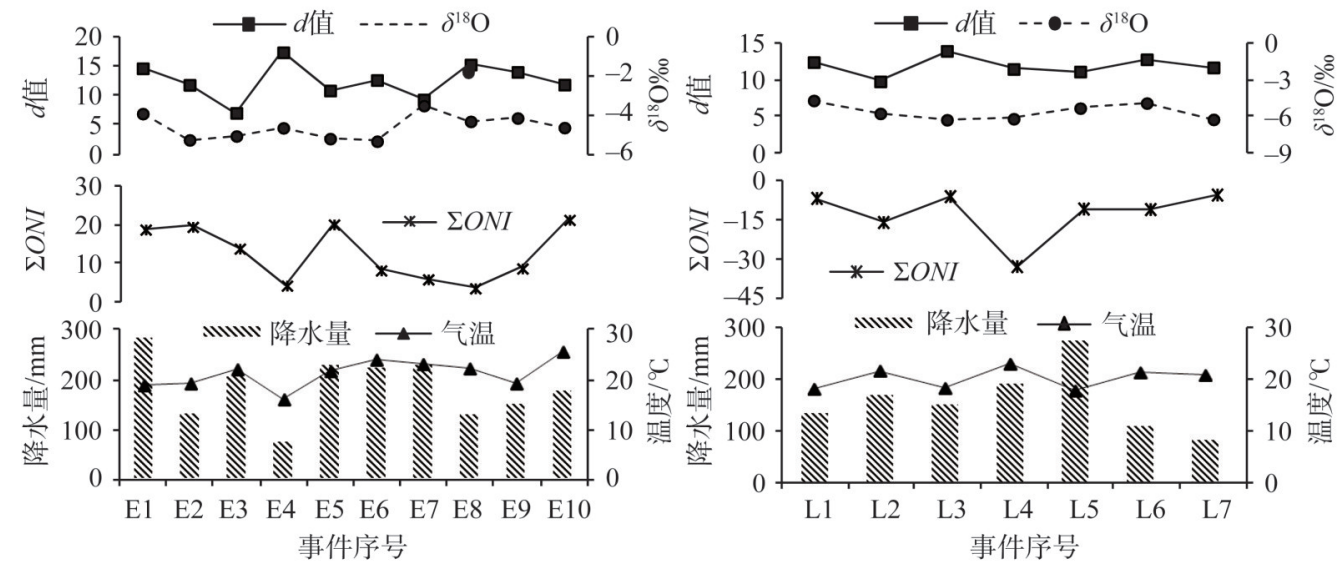

图 8 各事件年降水中 $\delta^{18} \mathrm{O} 、 d 、 \Sigma O N I$ 、降水量及气温的变化

Fig. 8 Variations of $\delta^{18} \mathrm{O}, d, \Sigma O N I$, precipitation and temperature in each ENSO event 


\section{3 结论与讨论}

利用珠江中下游地区中国香港、广州、桂林和柳州四个站点的大气降水稳定同位素 及相关气象数据，运用 OLR 技术研究了 ENSO 事件对降水稳定同位素水平、特征的影 响, 主要结论如下:

（1）ENSO 事件显著影响稳定同位素的年际差异，主要通过影响降水的年内分配， 特别是雨季降水的时间分配状况而实现； ENSO 事件对大气降水线方程有着明显规律性 的影响，拉尼娜年凸显出海洋性较强的气候特征; 大气降水 $\delta^{18} \mathrm{O}$ 的环境效应以反温度效 应为主，拉尼娜年加强反温度效应，厄尔尼诺年减弱反温度效应。

（2）水汽源区 ITCZ 的位置、对流活动强度及气团运移过程很大程度上决定着稳定同 位素的特征，厄尔尼诺与拉尼娜年 ITCZ 的变化规律呈现出相反的趋势，其 OLR 场的变 化与研究区稳定同位素特征有着较强的对应关系; $d$ 值与 $\Sigma O N I$ 的绝对值呈现较为显著的 负相关关系, ENSO 事件发生时不同的水汽源区相对湿度特征是造成 $d$ 值年际差异的主要 因素; 证明利用OLR 数据能够很好地反演水汽源区的年内、年际变化过程，有助于深人 探索水汽源区变化对降水稳定同位素的影响，推进同位素水文学的研究。

本文基于 OLR 技术初步研究了ENSO 事件对珠江中下游地区降水中稳定同位素的影 响, 由于 ENSO 事件的影响机制及水汽源区变化的过程极为复杂，在未来工作中，应在 以下两个方面进行深人研究。首先, 珠江中下游地区大气降水线方程在不同事件背景下 的变化规律与上海地区相反，这说明 ENSO 事件对大气水线方程的影响具有显著的地域 差异性，但目前尚无更多的资料说明 ENSO 事件对水线方程产生影响的规律; 其次，香 港站表现出诸多特殊性的原因文中仅是推论, 目前还未有这一方面的专门研究, 今后将 基于更为丰富的数据继续推进对这一问题的探索，以期能够提出科学全面的解释。

\section{参考文献(References):}

[1] 许涛, 蔡健榕, 孙晓双, 等. 台风“杜鹃”降水 $\delta^{18} \mathrm{O}$ 的云雨区效应初探. 自然资源学报, 2018, 33(12): 2238-2248. [XU T, CAI J R, SUN X S, et al. A tentative study of "cloudy and rainy area effect" of the $\delta^{18} \mathrm{O}$ in the precipitation of Typhoon "Dujuan". Journal of Natural Resources, 2018, 33(12): 2238-2248.]

[2] 姚檀栋, 朴世龙, 沈妙根, 等. 印度季风与西风相互作用在现代青藏高原产生连锁式环境效应. 中国科学院院刊, 2017, 32(9): 976-984. [YAO T D, PIAO S L, SHEN M G, et al. Chained impacts on modern environment of interaction between Westerlies and Indian Monsoon on Tibetan Plateau. Bulletin of Chinese Academy of Sciences, 2017, 32(9): 976-984.]

[3] PENG T R, WANG C H, HUANG C C, et al. Stable isotopic characteristic of Taiwan's precipitation: A case study of western Pacific monsoon region. Earth \& Planetary Science Letters, 2010, 289(3-4): 357-366.

[4] BREITENBACH S F M, ADKINS J F, MEYER H, et al. Strong influence of water vapor source dynamics on stable isotopes in precipitation observed in Southern Meghalaya, NE India. Earth and Planetary Science Letters, 2010, 292(1-2): 212-220.

[5] 赵㑆, 陈仕涛, 崔英方, 等. 神农架石笋记录的近 200年东亚季风变化及其ENSO 响应. 地理研究, 2015, 34(1): 74-84. [ZHAO K, CHEN S T, CUI Y F, et al. East Asian monsoon changes and its ENSO response revealed by a 200-year stalagmite record from Yongxing Cave on the Mountain Shennongjia. Geographical Research, 2015, 34(1): 74-84.]

[6] KURITA N. Water isotopic variability in response to mesoscale convective system over the tropical ocean. Journal of Geophysical Research Atmospheres, 2013, 118(18): 10376-10390.

[7] TREMOY G, VIMEUX F, MAYAKI S, et al. A1-year long $\delta^{18} \mathrm{O}$ record of water vapor in Niamey (Niger) reveals insight- 
ful atmospheric processes at different timescales. Geophysical Research Letters, 2012, 39(8): 85-93.

[8] VIMEUX F, TREMOY G, RISI C, et al. A strong control of the South American SeeSaw on the intra-seasonal variability of the isotopic composition of precipitation in the Bolivian Andes. Earth \& Planetary Science Letters, 2011, 307(1-2): 47-58.

[9] GAO J, MASSON-DELMOTTE V, YAO T, et al. Precipitation water stable isotopes in the South Tibetan Plateau: Observations and modeling. Journal of Climate, 2011, 24(13): 3161-3178.

[10] HE Y, RISI C, GAO J, et al. Impact of atmospheric convection on South Tibet summer precipitation isotopologue composition using a combination of in situ measurements, satellite data, and atmospheric general circulation modeling. Journal of Geophysical Research Atmospheres, 2015, 120(9): 3852-3871.

[11] 薛积涁, 钟巍, 赵引娟, 等. 珠江三角洲地区降水中 $\delta^{18} \mathrm{O}$ 的变化特征及与 ENSO 的关系. 地理科学, 2007, 27(6): 825830. [XUE J B, ZHONG W, ZHAO Y J, et al. Variations of $\delta^{18} \mathrm{O}$ in precipitation in the Zhujiang (Pearl) River delta and its relationship with ENSO event. Scientia Geographica Sinica, 2007, 27(6): 825-830.]

[12] 黄一民, 宋献方, 章新平, 等. 洞庭湖流域降水同位素与 ENSO 关系研究. 地理科学, 2017, 37(5): 792-798. [HUANG Y M, SONG X F, ZHANG X P, et al. Relationship of stable water isotopes in precipitation with ENSO in Dongting Lake Basin. Scientia Geographica Sinica, 2017, 37(5): 792-798.]

[13] 董小芳, 杨华玮, 张峦, 等. ENSO 事件对上海降水中氢氧同位素变化的影响. 环境科学, 2017, 38(12): 4991-5003. [DONG X F, YANG H W, ZHANG L, et al. Influence of ENSO events on the hydrogen $\left(\delta^{2} \mathrm{H}\right)$ and oxygen $\left(\delta^{18} \mathrm{O}\right)$ isotopic values of precipitation in Shanghai. Environmental Science, 2017, 38(12): 4991-5003.]

[14] 郭政昇, 郑国璋, 赵培, 等. 水汽源区变化对黄河中游降水稳定同位素的影响. 自然资源学报, 2018, 33(11): 19791991. [GUO Z S, ZHENG G Z, ZHAO P, et al. Effect of variation in water source area on stable isotopes in precipitation in the middle reach of the Yellow River Basin. Journal of Natural Resources, 2018, 33(11): 1979-199.]

[15] VINCENT D G, FINK A, SCHRAGE J M, et al. High- and low-frequency intraseasonal variance of OLR on annual and ENSO timescales. Journal of Climate, 2010, 11(5): 968-986.

[16] KASKAOUTIS D G, HOUSSOS E E, SOLMON F, et al. Impact of atmospheric circulation types on Southwest Asian dust and Indian summer monsoon rainfall. Atmospheric Research, 2018, 2(1): 189-205.

[17] CHAUDHARI H S, HAZRA A, POKHREL S, et al. SST and OLR relationship during Indian summer monsoon: A coupled climate modelling perspective. Meteorology and Atmospheric Physics, 2018, 130(2): 211-225.

[18] TANG Y, PANG H, ZHANG W, et al. Effects of changes in moisture source and the upstream rainout on stable isotopes in precipitation: A case study in Nanjing, eastern China. Hydrology and Earth System Sciences, 2015, 12(4): 3919-3944.

[19] 刘丙军, 陈晓宏, 曾照发. 珠江流域下游地区降水空间分布规律研究. 自然资源学报, 2010, 25(12): 2123-2131. [LIU B J, CHEN X H, ZENG Z F. Spatial distribution law of rainfall in the lower reaches of the Pearl River Basin. Journal of Natural Resources, 2010, 25(12): 2123-2131.]

[20] 尹焕玲, 钟巍, 马巧红, 等. 极端天气事件下广州市大气降水 $\delta^{18} \mathrm{O}$ 的变化特征研究. 华南师范大学学报: 自然科学版, 2012, 44(4): 121-127. [YIN H L, ZHONG W, MA Q H, et al. Variational characteristics of $\delta^{18} \mathrm{O}$ in precipitation in Guangzhou under extreme weather events. Journal of South China Normal University: Natural Science Edition, 2012, 44 (4): 121-127.]

[21] XIE L, WEI G, DENG W, et al. Daily $\delta^{18} \mathrm{O}$ and $\delta \mathrm{D}$ of precipitations from 2007 to 2009 in Guangzhou, South China: Implications for changes of moisture sources. Journal of Hydrology, 2011, 400(3-4): 477-489.

[22] 涂林玲, 王华, 冯玉梅. 桂林地区大气降水的 D 和 ${ }^{18} \mathrm{O}$ 同位素的研究. 中国岩溶, 2004, 23(4): 304-309. [TU L L, WANG H, FENG Y M. Research on D and ${ }^{18} \mathrm{O}$ isotope in the precipitation of Guilin. Carsologica Sinica, 2004, 23(4): 304-309.]

[23] 吴夏, 朱晓燕, 张美良, 等. 大气降水中稳定同位素组成的高分辨率记录: 以桂林地区为例. 长江流域资源与环境, 2013, 22(2): 182-188. [WU X, ZHU X Y, ZHANG M L, et al. High resolution stable isotope record of atmospheric precipitation in Guilin. Resources and Environment in the Yangtze Basin, 2013, 22(2): 182-188.]

[24] 陈虹颖, 徐峰, 李晓惠, 等. 近 65 年 ENSO 事件强度变化及时频特征研究. 热带气象学报, 2017, 33(5): 683-694. [CHEN H Y, XU F, LI X H, et al. Intensities and time-frequency variability of ENSO in the last 65 years. Journal of Tropical Meteorology, 2017, 33(5): 683-694.] 
[25] 郭政昇, 王娟, 赵培. 珠江流域大气降水稳定性氢氧同位素特征. 水文, 2017, 37(2): 78-82. [GUO Z S, WANG J, ZHAO P. Characteristics of hydrogen and oxygen stable isotopes in precipitation in Pearl River Basin. Journal of China Hydrology, 2017, 37(2): 78-82.]

[26] YURTSEVER Y, GAT J R. Atmospheric waters. In: GAT J R, GON-FIANTINI R, eds. Stable isotope hydrology: Deuterium and oxygen-18 in the water cycle. Vienna: International Atomic Energy Agency, 1981: 103-142.

[27] LIU J, SONG X, YUAN G, et al. Stable isotopic compositions of precipitation in China. Tellus B: Chemical and Physical Meteorology, 2014, 66(1): 39-44.

[28] 柳鉴容, 宋献方. 中国东部季风区大气降水 $\delta^{18} \mathrm{O}$ 的特征及水汽来源. 科学通报, 2009, 54(22): 3521-3531. [LIU J R, SONG X F. Characteristics of $\delta^{18} \mathrm{O}$ in precipitation over Eastern Monsoon China and the water vapor sources. Chinese Science Bulletin, 2009, 54(22): 3521-3531.]

[29] ZHANG M, WANG S. A review of precipitation isotope studies in China: Basic pattern and hydrological process. Journal of Geographical Sciences, 2016, 26(7): 921-938.

[30] 张冲. 1950 年以来 ENSO 事件对我国气候影响研究. 西安: 陕西师范大学, 2012. [ZHANG C. Impact of ENSO events on China's climate since 1950. Xi'an: Shaanxi Normal University, 2012.]

[31] 张辅成. 深圳与香港及广州气温、降水相关的分析.气象, 1989, 15(6): 43-45. [ZHANG F C. Analysis of temperature and precipitation in Shenzhen and Hongkong and Guangzhou. Meteorological Monthly, 1989, 15(6): 43-45.]

[32] ROPELEWSKI C F, HALPERT M S. Global and regional scale precipitation patterns associated with the El Niño/Southern Oscillation. Monthly Weather Review, 2013, 115(8): 985-996.

[33] 孙从建, 张子宇, 李捷, 等. 青藏高原西北部大气降水稳定同位素时空特征变化. 山地学报, 2018, 36(2): 217-228. [SUN C J, ZHANG Z Y, LI J, et al. Temporal and spatial characteristics of stable isotopes of atmospheric precipitation in the northwestern Tibetan Plateau. Mountain Research, 2018, 36(2): 217-228.]

[34] DANSGAARD W. Stable isotopes in precipitation. Tellus, 1964, 15(4): 436-468.

[35] 李广, 章新平, 宋松, 等. 中国不同水体中 $\delta \mathrm{D}$ 与 $\delta^{18} \mathrm{O}$ 研究进展. 气象与环境学报, 2016, 32(4): 132-138. [LI G, ZHANG X P, SONG S, et al. Research progress of $\delta \mathrm{D}$ and $\delta^{18} \mathrm{O}$ in different water bodies in China. Journal of Meteorology and Environment, 2016, 32(4): 132-138.]

[36] JOUZEL J, MERLIVAT L. Deuterium and oxygen 18 in precipitation: Modeling of the isotopic effects during snow formation. Journal of Geophysical Research Atmospheres, 1984, 89(D7): 11749-11757.

[37] 王钦, 李双林, 付建建, 等. 1998 和 2010 年夏季降水异常成因的对比分析: 兼论两类不同厄尔尼诺事件的影响. 气象 学报, 2012, 70(6): 1207-1222. [WANG Q, LI S L, FU J J, et al. On the formation of anomalous summer precipitation in the years of 2010 and 1998: A comparison of the El Niño's impact between modoki and typical El Niño case. Acta Meteorologica Sinica, 2012, 70(6): 1207-1222.] 


\title{
Influence of ENSO events on the hydrogen and oxygen isotopes of precipitation in the middle and lower reaches of Pearl River
}

\author{
GUO Zheng-sheng ${ }^{1}$, ZHENG Guo-zhang ${ }^{1,2}$, CAO Fu-Qiang ${ }^{1}$, ZHAO Pei $^{3}$, XIAO Jie $^{1}$ \\ (1. College of Geographical Sciences, Shanxi Normal University, Linfen 041000, Shanxi, China; 2. College of \\ Environment and Economics, Shanxi University of Finance \& Economics, Taiyuan 030006, China; 3. College of \\ Urban, Rural Planning and Architectural Engineering, Shangluo University, Shangluo 726000, Shaanxi, China)
}

\begin{abstract}
The characteristics of stable isotopes in precipitation are influenced by moisture transport path, rainfall amount, temperature, humidity, elevation and so on. El Niño-Southern Oscillation (ENSO) is one of the strongest signals of Global Coupled Ocean-Atmosphere and an important factor influncing the inter- annual climate change. The variation of moisture sources and the ENSO events prominently affect the processes of hydrological cycle and characteristics of precipitation isotope in the East Asian monsoon region. Based on the isotopic values of precipitation and Outgoing Longwave Radiation (OLR) data from four stations of GNIP (Hong Kong, Guangzhou, Guilin, Liuzhou) in the middle and lower reaches of the Pearl River, the spatial distribution and temporal characteristics of $\delta^{18} \mathrm{O}$ in precipitation were studied under the background of ENSO. The results show that the ENSO event was the main factor which affected the inter-annual variation of stable isotopes in precipitation in the middle and lower reaches of the Pearl River by impacting the annual distribution of precipitation especially in the rainy season. The slope and intercept of the Meteoric Water Line in normal year were larger than those in El Nino year and smaller than those in La Niña year. La Niña year highlighted the strong characteristics of marine climate. The $\delta^{18} \mathrm{O}$ in precipitation showed antitemperature effect. This phenomenon was strengthened in La Niña year and weakened in El Niño year. The position of Intertropical Convergence Zone (ITCZ) in moisture sources, intensity of convective activity and the process of air mass migration largely determined the characteristics of stable isotopes. The scope and strength of ITCZ in La Niña and El Niño years showed the opposite trend. The variation of OLR field had a strong correspondence with the stable isotope characteristics in the study region. There was a significant negative correlation between $d$-excess and the intensity of ENSO events. The relative humidity characteristic of moisture sources in different ENSO events was the main factor causing the inter- annual difference of the $d$-excess. This research, focusing on the effect of ENSO events on the hydrogen and oxygen isotopic characteristics of precipitation in the middle and lower reaches of the Pearl River, was helpful to understand the moisture sources and the changes of precipitation process in China's monsoon region, and to further promote the research on the mechanism of water circulation in monsoon region.
\end{abstract}

Keywords: stable isotopes; ENSO; OLR field; ITCZ; the middle and lower reaches of the Pearl River 